\title{
Studies on the effect of $\mathrm{NH}_{4} \mathrm{HCO}_{3}$ treatment on roughage degradation and rumen microbial synthesis
}

\author{
JQ Wang, Q Zhang \\ Animal Science institute, Chinese Academy of Agricultural Sciences, Yuanmingyuan \\ west road 2, Haidian, Beijing 100094, China
}

\begin{abstract}
Corn stover and rice straw are two main kinds of roughages fed to ruminants in China. The present research was carried out to study the effects of $\mathrm{NH}_{4} \mathrm{HCO}_{3}$ treatment on their degradation estimated with nylon bag method and the microbial synthesis measured with rumen simulation technique (RST). $10 \%$ $\mathrm{NH}_{4} \mathrm{HCO}_{3}$ and $40 \%$ water were added to corn stover and rice straw on DM basis, and heated at $65^{\circ} \mathrm{C}$ for 7 hours. Four roughage samples, corn stover (CS), treated corn stover (TCS), rice straw (RS) and treated rice straw (TRS), were prepared.
\end{abstract}

The nylon bag method ( $\varnothing$ rskov and Mc Donald, 1979, J Agric Sci, 92, 499-503) and the equations $d p=a+b\left(1-e^{-c t}\right)$ and $P=a+$ $(b c /(c+k))$ were used to study the degradation kinetic changes of untreated and treated samples (see table). For both corn stover and rice straw, $\mathrm{NH}_{4} \mathrm{HCO}_{3}$ treatment did not change the rapid degradable fraction "a" $(P>0.05)$, but improved the potential degradable part " $\mathrm{b}$ " and the degradation rate constant " $c$ " $(P<0.05)$. The treatment increased the effective degradability $P$ of corn stover by 8.9 percentage units $(P<0.05)$ and of rice straw by 8.0 percentage units $(P<0.05)$.

The results from RST showed that $\mathrm{NH}_{4} \mathrm{HCO}_{3}$ treatment increased the amount of fermentable OM (FOM), non ammonia $N$ (NAN) and microbial $N$ (MN) for both roughages $(P<0.05)$. The efficiencies of microbial synthesis (MN/FOM, $g / \mathrm{kg}$ ) were not different for CS, TCS, RS and TRS $(P>0.05)$.

In conclusion, $\mathrm{NH}_{4} \mathrm{HCO}_{3}$ treatment can increase the fermentable OM of CS and RS in the rumen, mainly from " $\mathrm{c}$ " fraction and " $\mathrm{c}$ " without changing " $a$ " fraction. The effective degradabilities can be improved from $37.3 \%$ to $46.2 \%$ for CS and from $35.5 \%$ to $43.5 \%$ for RS. The treatment of CS and RS with $\mathrm{NH}_{4} \mathrm{HCO}_{3}$ can increase the amount of FOM and $\mathrm{MN}$ synthesis with no influence on the fermentable energy efficiencies.

$\begin{array}{ccc}\text { Nylon bag mehtod } & & \text { CS } \\ \text { parameters : } & \text { a } & \\ & \text { b } & 13.8 \\ & \mathrm{c} & 48.3 \\ & \mathrm{p} & 0.0312 \\ & & 37.3\end{array}$

RST technique

FOM (\% OM)

47.6

NAN $(\mathrm{mg} / \mathrm{d})$

720

MN (mg/d)

494

MN/FOM $(\mathrm{g} / \mathrm{kg})$

\begin{tabular}{ccc} 
TCS & RS & TRS \\
\cline { 2 - 3 } 13.1 & 15.7 & 14.9 \\
58.3 & 39.6 & 54.8 \\
0.0434 & 0.0329 & 0.0360 \\
46.2 & 35.5 & 43.5 \\
(outflow rate constant K $=0.0333$ ) & \\
& & \\
54.0 & 45.4 & 52.8 \\
770 & 700 & 760 \\
554 & 483 & 540 \\
24.2 & 23.3 & 23.9 \\
\hline
\end{tabular}

